\title{
Celestina: Documento bibliográfico (suplemento número 43)
}

\author{
Amaranta Saguar García \\ Universidad Complutense de Madrid \\ Devid Paolini \\ The City College of New York
}

2835. BASTIANES, María, "Una versión polémica de La Celestina. La adaptación de Michel Garneau traducida para la escena española», Talía. Revista de Estudios Teatrales 3 (2021), 109-124. <https://doi. org/10.5209/tret.66471>.

Este artículo se propone estudiar la versión de Celestina de Michel Garneau (Célestine là-bas près des tanneries au bord de la rivière) y la polémica traducción que realizó Álvaro García Meseguer para la puesta en escena española de Robert Lepage en 2004. De esta manera, se llevará a cabo un análisis formal detallado y exhaustivo del texto que permita dilucidar, de manera objetiva, cuáles fueron las características, aportaciones y problemas del texto dentro del espectáculo y en relación con la historia escénica de la pieza en España. Para ello se ha utilizado un modelo de análisis inspirado en el método propuesto por José Luis García Barrientos para comentar textos dramáticos y en las consideraciones de María Rosa Lida de Malkiel acerca de los recursos teatrales en la obra de Rojas. Se estudiará también el peso de los personajes en la adaptación con un método cuantitativo similar al empleado por José Romera Castillo en su estudio de la versión de 1988 de Gonzalo Torrente Ballester [resumen de la autora].

2836. BELTRÁN, Rafael, "Del suicidio de Judas al salto de Pármeno: codicia, traición y caídas mortales en La Celestina", Celestinesca 44 (2020): 9-80. <https://doi.org/10.7203/Celestinesca.44.19428>.

El artículo se propone el estudio de las influencias de los motivos de la traición y suicidio de Judas Iscariote en las caídas mortales de cuatro personajes principales de La Celestina. Judas encarna, mejor que ningún otro personaje bíblico, la trayectoria del pecador, desde la lealtad 
y la traición hasta la desesperación y la muerte suicida. Se examina la figura literaria e iconográfica de la codicia, traición y suicidio de Judas en la Edad Media, centrándonos en los dos tipos de suicidio que refleja la Biblia. Se analizan las caídas accidentales (Calisto), los saltos mortales al vacío (Sempronio y Pármeno) y el suicidio (Melibea); las imágenes de representación de la traición (la bolsa de las monedas); y, finalmente, la trayectoria de Pármeno, que va, como la de Judas, desde fidelidad del buen criado, pasando por la codicia y la traición, hasta el salto mortal hacia el vacío desesperado [resumen del autor].

2837. BERNALDO DE QUIRÓS, José Antonio. «Fernando de Rojas y el primer acto de La Celestina. Algunas preguntas que esperan respuesta», Tonos Digital, 32 (2017), s.p. [en línea, <http://www.tonosdigital. com/ojs/index.php/tonos/article/view/1627>, fecha de consulta: 12 de diciembre de 2021].

Se ha generalizado bastante la idea de que Fernando de Rojas es el autor de La Celestina a partir del segundo acto. Sin embargo, esta visión de la autoría se enfrenta a una serie de graves problemas a los que hasta ahora no se ha dado solución, por lo que en este trabajo se afirma que debe ser considerada inadecuada. Además, se intenta mostrar que los argumentos en que se basa son frágiles y hasta contradictorios entre sí [resumen del autor].

2838. BLINI, Lorenzo, "Testo antico e traduzione moderna: La Celestina in italiano", en Interpretar traducir textos de la(s) cultura(s) hispánica(s). Atti del Convegno internazionale "Interpretare tradurre testi delle culture ispaniche», Forlì, 21-23 ottobre 1999. Bologna: CLUEB, 2000, 1000-1025. $<$ https://doi.org/10.1400/32036>.

Algunas reflexiones sobre los problemas de traducción de textos literarios diacrónicos analizando, en particular, algunas versiones al italiano de LC (en total, cinco traducciones publicadas entre 1943 y 1995).

2839. BRIS GARCÍA, Juan, «La recreación del Juicio de Paris en la Comedia de Calisto y Melibea», Forvm Classicorvm II (2021), 1121-1129.

Identificación y comentario de las referencias a y reminiscencias del juicio de Paris en Celestina, al que se le atribuye una función estructural y simbólica que influye sobre el texto. Más allá de las alusiones explícitas y su recurrencia a lo largo del texto, interesa cómo el contraste entre la descripción idealizada de Calisto y la discusión sobre el físico de Melibea en la escena del banquete pueden leerse como guiño hacia el juicio de Paris, inaugurando casi la tradición de parodiar este episodio mitológico en el Siglo de Oro. 
2840. BROWN, Kenneth, « A qué se refiere la voz «esto» en el enunciado inicial de Calisto, La Celestina, acto 1": "En esto veo, Melibea, la grandeza de Dios"?», Crónicas 49 (2021), 18-20.

Relaciona la afirmación de Calisto sobre la grandeza de Dios con la expresión "Gadol Adonai» de los Salmos (salmo CXLV) y, a partir de ahí, con otros textos judíos. Esto lleva al autor a afirmar que la primera escena de Celestina tiene lugar en una sinagoga. Añade toda una serie de pequeños detalles de la escena inicial que pueden estar apuntando a un contexto judío o judaizante, como la sonoridad de «En esto veo, Melibea, la grandeza de Dios/Dío» o los nombres de los protagonistas. Acaba defendiendo que los cripto-judeoespañoles podían usar el pronombre demostrativo neutro "esto" para hacer referencia a su fe.

2841. CAMACHO, Ginette Alomar, «Huellas judío-conversas en los prólogos de La Celestina y el Lazarillo de Tormes", en Morada de la palabra: homenaje a Luce y Mercedes López-Baralt, ed. William Mejías López. San Juan de Puerto Rico: Universidad de Puerto Rico, 2002, 91-101.

Un análisis de la carta «El autor a un su amigo» y de los prólogos de $L C$ y el Lazarillo en clave judío-conversa.

2842. CANET, José Luis, "Alphonso Hordognez versus Alonso Ordóñez. Sobre el traductor de La Celestina al italiano", Edad de Oro XL (2021), 97-108. <https://doi.org/10.15366/edadoro2021.40.004>.

Examen de la documentación histórica sobre Alonso Ordóñez, profesor del Estudio General de Valencia; retrato intelectual de Alphonso Hordognez, traductor de Celestina al italiano y familiar del papa Julio II, y presentación del religioso Alphonsus Hordogniez, palafrenero de León X, cuyo perfil encaja mucho más con el del traductor de Celestina que el del profesor valenciano. Descarta, igualmente, que estos dos puedan ser la misma persona.

2843. CÁSEDA TERESA, Jesús Fernando, "La Segunda Celestina de Feliciano de Silva a la luz de nuevos datos sobre su biografía», Celestinesca 44 (2020): 81-106 [en línea, <https://doi.org/10.7203/Celestinesca.44.19429>.

Este estudio aporta un buen número de documentos desconocidos que dan luz sobre la biografía de Feliciano de Silva, localizados en el Archivo Histórico de la Nobleza. Da noticia de su fecha de nacimiento (1479), asunto que tanto debate ha suscitado a lo largo de los años, y desvela muchos aspectos relativos a su familia, a su situación económica, etc. Establece el origen de diversos personajes de su continuación de La Celestina a partir de su biografía: su primo el «arcediano» o el "arcediano el viejo», Polandria su esposa Gracia Fe, Celesti- 
na probablemente Catalina Maldonado, etc. Estudia algunas curiosas relaciones onomásticas de la obra con los nombres que aparecen en otras obras de sus amigos judeoconversos portugueses o de Núñez de Reinoso. Y sitúa el origen de otros muchos personajes de su comedia: por ejemplo el juego onomástico con su propio nombre en el caso de "Félides o Filínides», que ocultan en ambos casos a Feliciano de Silva [resumen del autor].

2844. COOPER, Helen, "La Celestina and the Reception of Spanish Literature in England", en Iberian Chivalric Romance. Translations and Cultural Transmission in Early Modern England, ed. Leticia Álvarez-Recio. Berlin, Boston: De Gruyter, 2021, 233-246. <https://doi.org/10.3138/9781487539009-014>.

El trabajo se centra en la recepción de la obra de Rojas en Inglaterra y se enfoca, en particular, en el Interludio de Rastell y la traducción de Mabbe.

2845. CROCOLL, Natacha, "Manipulation and Secrecy: Hidden Places of Love in La Celestina", en Geheimnis und Verborgenes im Mittelalter, ed. Stephan Conermann, Harald Wolter-von dem Knesebeck and Miriam Quiering. Berlin, Boston: De Gruyter, 2021, 393-408. <https:// doi.org/10.1515/9783110698541-021>.

La investigación se enfoca en el análisis del secreto y la manipulación que se detectan, a lo largo del texto, no solo en las acciones de los personajes, sino también en elementos que forman parte del «escenario» en que aquellos se mueven: las puertas, las casas, la torre de Pleberio, el jardín de la joven enamorada, etc. Aparentemente en la obra de Rojas sí hay lugar para la manipulación, pero no para el secreto.

2846. DI CAMILLO, Ottavio. "De genealogia Celestinae o Celestina antes de la Celestina», en El Renacimiento literario en el mundo hispánico: de la poesía popular a los nuevos géneros del Humanismo, eds. Javier Burguillo y Aarón Rueda Benito. Salamanca: SEMYR, 2021, 25-58.

Como indica el título, el estudio se enfoca, con abundancia de detalles, en la espinosa cuestión de la génesis de LC - difícilmente explicable en una Castilla de finales del siglo XV donde los conocimientos teóricos y prácticos de la tradición teatral eran muy escasos-. En la segunda parte se señala la posible forma en que circuló la obra en un primer momento - la de farsa - y se vuelve a analizar la concomitancia de lecciones entre Mp y la traducción italiana —con evidentes consecuencias sobre el stemma codicum actualmente aceptado por la mayoría de la crítica- defendiendo, con razones ecdóticas, la posibilidad de que hubo primero una traducción de la CCM.

2847. ESTEBAN MARTÍN, Luis M., "Gaspar Gómez de Toledo y la búsqueda de la fama», Celestinesca 44 (2020): 393-404. <https://doi. org/10.7203/Celestinesca.44.19441>. 
Gaspar Gómez de Toledo, con su Tercera parte de la tragicomedia de Celestina, pretende no solo continuar la obra precedente, la Segunda Comedia de Celestina, de Feliciano de Silva, y entrar así en el ciclo celestinesco iniciado con la publicación de Celestina, sino convertirse en el autor con el que dicho ciclo quede cerrado definitivamente, de ahí que vaya concluyendo episodios inconclusos en la obra de Silva y que acabe definitivamente con la vieja alcahueta Celestina resucitada por Silva. Esta intención de cerrar un ciclo viene motivada por el deseo de fama, de pasar a la posteridad como el autor que culminó las aventuras de la alcahueta de Fernando de Rojas y, por tanto, gozar del éxito que el público otorgó a las dos obras que le precedieron [resumen del autor].

2848. FERNÁNDEZ GALLARDO, Luis, "Amor y matrimonio en $\mathrm{La} \mathrm{Ce}$ lestina. Puntos de vista de un jurista», Boletín de la Real Academia 100 (322), (2021): 419-460 [en línea, <http://revistas.rae.es/brae/article/ view/437>, fecha de consulta: 12 de diciembre de 2021].

La concepción del amor y del matrimonio que se muestra a través de los personajes de La Celestina revela coincidencias no triviales con la doctrina del Derecho Común, dada la condición de jurista de Fernando de Rojas: naturaleza de la pasión amorosa como furor, sexualidad de los criados, incompatibilidad entre matrimonio y pasión amorosa, papel de los padres en la elección del cónyuge. Se matiza y precisa así el alcance y naturaleza de la cortesanía erótica presente en $\mathrm{La} C$ elestina, que muestra su arraigo en la realidad social e ideológica de la Castilla del siglo XV [resumen del autor].

2849. FERRERA-LAGOA, Alberto, ««Muchos días son passados...»: Magia y concepción del tiempo en La Celestina», Celestinesca 44 (2020): 107-144. <https://doi.org/10.7203/Celestinesca.44.19430>.

En este artículo se analizan las referencias textuales de La Celestina que evidencian tanto la existencia del elemento mágico en la obra como su importancia estructural. Para ello, se ofrecen nuevos datos en favor de la hipótesis del enamoramiento de Melibea como consecuencia del conjuro celestinesco y se realiza un análisis comparativo entre los dos amantes y la retórica del amor cortés para descartar la hipótesis del tiempo implícito y aportar una nueva interpretación del amor entre Calisto y Melibea [resumen del autor].

2850. FRANÇOIS, Jéromine, "Conjúrote, triste Plutón...": Reescrituras contemporáneas de la hechicería de Celestina», en Storyca. Magia, brujería, Inquisición, ed. Antonio Huertas Morales, Valencia, PARNASEO - Universitat de València, 2019, 79-100 [en línea, <http://parnaseo. uv.es/AulaMedieval/aM_es/StorycaWeb/conjurote-triste-pluton-reescrituras-contemporaneas-de-la-hechiceria-de-celestina>, fecha de consulta: 02 de noviembre de 2020]. 
Estudio comparativo de cuatro reescrituras contemporáneas del conjuro de Celestina en "Dejemos al diablo...» de Azorín (capítulo de Los valores literarios, 1913), Razón y pasión de enamorados. Tragicomedia celestinesca en tres actos de Fernando Toro-Garland (1973), Una noche en la picota de Luis García Jambrina (inédita, 2012) y Ojos de agua de Álvaro Tato (2014). La primera desvirtúa el conjuro para demostrar su carácter ornamental, la segunda incide en este carácter decorativo y lo reduce a una simple convención, y la tercera descubre que la alcahueta no tiene ni ha tenido vía directa con lo sobrenatural, sino que se trata de un mero fingimiento. Por su parte, la cuarta recupera la Celestina hechicera y convierte sus conocimientos en esta materia en rasgo definidor del personaje, atribuyendo incluso el éxito a lo largo del tiempo de la Tragicomedia de Calisto y Melibea a un nuevo conjuro suyo con este fin. $\mathrm{Al}$ final, lo que las cuatro obras tienen en común es su toma de partido en la discusión crítica sobre el papel de la magia en Celestina y el reconocimiento del conjuro a Plutón como un elemento imprescindible a la hora de establecer un diálogo intertextual con su modelo.

2851. FRANÇOIS, Jéromine, "Celestina", en La mitificación del pasado español. Reescrituras de figuras y leyendas en la literatura del siglo XIX, eds. Elizabeth Amann, Fernando Durán López, María José González Dávila, Alberto Romero Ferrer y Nettah Yoeli-Rimmer. Madrid - Frankfurt: Iberoamericana - Vervuert, 2018, 63-82. <https://doi. org/10.31819/9783954876877-006>.

Repaso del resurgimiento de Celestina en el siglo xIx y del camino hacia su consagración como mito literario. Aparte del panorama general, incluye el análisis de tres hitos literarios decimonónicos: Los polvos de la madre Celestina de Juan Eugenio Hartzenbusch (1840), el artículo costumbrista "La Celestina» de Serafín Estébanez Calderón, incluido en el tomo segundo de su Los españoles pintados por sí mismos (1844) y la reinterpretación de Celestina por la Generación del 98. El primero inicia la tendencia a exagerar la dimensión hechiceril de la alcahueta, que en el segundo va adquiriendo tonalidades más malignas y, en lugar de servir de recurso para situaciones cómicas y para satisfacer las convenciones del género de la comedia de magia, va a servir para introducir cierta crítica social relacionada con la discusión contemporánea sobre el papel de las alcahuetas y la legalización de la prostitución. Por su parte, los autores del 98 ven en Celestina un símbolo nacional y lo usan para ilustrar sus ansiedades sobre el momento histórico que viven. No obstante, a pesar de estas diferencias, todos comparten una marcada conciencia literaria sobre lo que ha llevado al personaje a sobrevivir hasta sus días, que se reflejará especialmente en las reescrituras de los autores del 98 y en sus reflexiones críticas, que marcarán la entrada del personaje en el siglo xx. 
2852. FRANÇOIS, Jéromine, "Celestina, mediadora espacial en Terra Nostra (1975), de Carlos Fuentes», en Dimensiones: el espacio y sus significados en la literatura hispánica, ed. Raquel Crespo-Vila y Sheila Pastor, Madrid: Biblioteca Nueva, 2017, 431-440.

Presenta las diferentes Celestinas que aparecen en Terra Nostra de Carlos Fuentes (1975) y describe sus respectivas caracterizaciones, funciones y actuaciones dentro del relato. Concluye que la función principal que desempeñan es la de mediadora, dando una nueva dimensión al papel de intermediaria de la Celestina original que se extiende a terrenos como el geográfico (Europa y América), el temporal (Edad Media y Contemporánea), el identitario (identidad española e identidad americana) o el narrativo (marcos y relatos intercalados). Gracias a su mediación los otros personajes encuentran su destino, por lo que funciona como auténtico motor de la obra. Pero también es un referente subversivo, que desestabiliza sus mundos.

2853. FRANÇOIS, Jéromine, «Del personaje transficcional al mito: crossover y coalescencia de Celestina en Terra Nostra», en El personaje transficcional en el mundo hispánico, ed. Álvaro Ceballos Viro y Jéromine François, Liège: Université de Liège, 2018, 67-82.

Estudio de los entrecruzamientos de Celestina con otros personajes transficcionales en la obra Terra Nostra de Carlos Fuentes (1975). Tras el necesario repaso de la presencia del personaje de Celestina en la misma, se comentan sus encuentros con don Quijote y don Juan, con quienes comparte la caracterización de antihéroe rebelde. Ninguno de los tres aparece con todos sus atributos característicos, pero sí se mantienen alusiones a los textos originales de los que proceden, si bien no necesariamente asociados con el personaje que sería de esperar: así, los tres clásicos literarios se entremezclan e intercambian. Esta intercambiabilidad desempeña una función lúdica, orientada a un público hispánico que no solo esté muy familiarizado con las tres obras, sino que se reconozca en esos tres personajes, sin lo cual pierde en efectividad. Distinto es el caso del entrecruzamiento con la deidad azteca Tlazoltéotl: aunque esta figura en el texto bajo la identidad de la Señora de las mariposas, lo cierto es que las Celestinas de Terra Nostra asumen características y funciones de la misma, que intensifican su presencia. Así, en un solo personaje, el de Celestina, se manifiestan distintas posibilidades de coalescencia y entrecruzamiento con otros personajes transficcionales.

2854. FRANÇOIS, Jéromine, «Los clásicos de la alcahueta: intertextualidad grecolatina en La Lozana andaluza», en Dueñas, cortesanas y alcahuetas: "Libro de buen amor», "La Celestina" y "La Lozana andaluza", Alcalá la Real: Ayuntamiento de Alcalá la Real, 2017, 71-94 [en línea, <https://cvc. 
cervantes.es/literatura/arcipreste_hita/05/fran\%C3\%A7ois.htm>, fecha de consulta: 23 de octubre de 2019].

El estudio se centra en el análisis de la intertextualidad grecolatina en la Lozana señalando de qué manera esta se realiza y si, tras una recontextualización convencional de pasajes e ideas clásicas, se esconde además una subversión de los mismos.

2855. FUNES, Leonardo, «La vida a manera de contienda: conflicto social y universo femenino en Celestina", Revista Melibea 13.2 (2019), 56-70 [en línea, <https://bdigital.uncu.edu.ar/15670>, fecha de consulta: 13 de diciembre de 2021].

Contrasta el papel secundario de la mujer en la sociedad medieval y el de objeto tanto en el discurso literario del amor cortés como en el debate sobre la condición femenina del siglo XV con la atención que Celestina concede a los personajes femeninos. Se destaca que los personajes femeninos tienen voz propia que, además, es realmente femenina, no una impostación, y refleja una auténtica subjetividad femenina. El lugar donde más evidente resulta esto es en la expresión del deseo erótico, que pone de manifiesto las contradicciones a las que la mujer está sometida en el terreno amoroso, pero también del deseo de autonomía, que la posición de la mujer en la sociedad no ayuda a alcanzar y menos a mantener por mucho tiempo.

2856. FUNES, Leonardo, y Gladys LIZABE, "Celebrando 520 años de La Celestina. Videoconferencia a Joseph Thomas Snow sobre Celestina", Revista Melibea 13.2 (2019), 32-55 [en línea, <https://bdigital.uncu. edu.ar/15669>, fecha de consulta: 13 de diciembre de 2021].

En esta videoconferencia, Joseph Snow dialoga con un grupo de jóvenes universitarios de la Universidad Nacional de Cuyo (Argentina) y monologa consigo sobre lo que sus ojos de lector experto y avezado le han permitido descubrir en Celestina a lo largo de años de lecturas y re-lecturas. De forma amena y muy didáctica, recorre el mundo de sus personajes, de sus conflictos y deseos y acerca la complejidad del mundo celestinesco a lectores del siglo XXI que se sorprenden por su humanidad y modernidad, y que podrán enseñarla en distintos niveles y modalidades de la educación. Los profundos conocimientos y lecturas expertas y estratégicas del Dr. Snow de esta gran obra de la literatura española avivan y remozan un clásico de la literatura universal y renuevan su importancia en la formación de futuros profesores de Lengua y Literatura [resumen en línea; las páginas mencionadas al final de la entrada bibliográfica se refieren a la transcripción de dicha videoconferencia]. 
2857. GARCÍA ÁLVAREZ, Juan Pablo Mauricio, "Acercamientos críticos a la Tercera parte de la Tragicomedia de Celestina de Gómez de Toledo: nuevas perspectivas de la celestinesca», Celestinesca 44 (2020): 385392. <https://doi.org/10.7203/Celestinesca.44.19440>.

Presentación del dossier especial "Acercamientos críticos a la Tercera parte de la Tragicomedia de Celestina de Gómez de Toledo».

2858. GARCÍA ÁLVAREZ, Juan Pablo Mauricio,, "Materialización del dolor de Celestina en la Tercera parte de la Tragicomedia de Celestina», Celestinesca 44 (2020): 457-488. <https://doi.org/10.7203/Celestinesca.44.19444>.

En este artículo se analiza el dolor de Celestina como un elemento configurador del personaje en el texto escrito por Gómez de Toledo. Las heridas físicas y emocionales se convierten en una materialización de los valores morales y sociales de la vieja, mostrando con ello un tratamiento original. El análisis del dolor nos permite construir una cultura emocional representada en la celestinesca [resumen del autor].

2859. GARCIA MUNIZ, Cleuza Andrea, "Hecker Filho e Millôr: tradutores de La Celestina no Brasil», Contexto 40.2 (2021), 165-190 [en línea, <https://www.periodicos.ufes.br/contexto/article/view/31876>, fecha de consulta: 14 de diciembre de 2021].

Tras contextualizar la recuperación de Celestina en Brasil en los años 60 , década en la que proliferan las adaptaciones escénicas y en las que se publica la primera traducción al portugués destinada al público brasileño, se analizan otras dos traducciones más actuales: la de Paulo Hecker Filho (1990) y la de Millôr Fernandes (2008). Se describe el tipo de información que cada traductor ofrece en los paratextos editoriales de sus respectivas traducciones, tanto sobre Celestina como sobre las estrategias traductorias aplicadas. Igualmente, se contextualiza cada traducción y se hace el perfil profesional de cada traductor, lo que servirá para explicar algunas de las decisiones autoriales. Se concluye que estas traducciones se alejan de la función de crítica sociopolítica que el texto había adoptado en los años 60 para tomar más conciencia de su carácter literario y sus posibilidades teatrales.

2860. GERNERT, Folke, "Crimen y castigo en la Tercera Celestina de Gaspar Gómez de Toledo: ¿la visión moralizadora de un médico?», Celestinesca 44 (2020): 431-456. <https://doi.org/10.7203/Celestinesca.44.19443>.

El presente artículo estudia la Tercera Celestina de Gaspar Gómez de Toledo como obra escrita posiblemente por un médico haciendo particular hincapié en las textualizaciones del saber curativo desde una perspectiva de la historia de la ciencia. Una comparación con La Lozana Andaluza del médico Francisco Delicado muestra paralelismos con 
la obra de Gómez de Toledo, quien, al igual que el galeno andaluz, emite juicios moralizantes a través de la metáfora de la enfermedad y de la minusvalía física [resumen de la autora].

2861. GÓMEZ CANSECO, Luis María, «Del catre al fogón: acuchilladas y mondongueras entre La Celestina y el Quijote apócrifo", en En la concha de Venus amarrado: erotismo y literatura en el Siglo de Oro, ed. Patricia Marín Cepeda. Madrid: Visor, 2017, 91-105.

Partiendo de la caracterización de Bárbara, personaje del Quijote de Avellaneda (1614), como mondonguera y cariacuchillada, se hace un repaso de otras ocurrencias literarias de estas características, entre las que nos interesan las de Celestina. En el caso de las cicatrices faciales, se destacan sus connotaciones prostibularias y sexuales. En el caso del mondongo, también tiene connotaciones sexuales $y$, en este sentido figurado, se relaciona con el mundo de la prostitución. Se trata, en realidad, de un trabajo sobre el personaje de Bárbara pero que resulta de interés para estudiar el motivo de la cuchillada en la cara de Celestina.

2862. GUERRY, François-Xavier, "Lecture croisée de Fernando de Rojas et de María de Zayas. L'intertexte célestinesque de La burlada Aminta», e-Spania, 40 (2021), s.p. <https://doi.org/10.4000/e-spania.41929>.

Rastreo de las posibles reminiscencias de Celestina (y sus continuaciones) en La burlada Aminta de María de Zayas (1637). Se destacan las semejanzas entre los personajes de Celestina y Elena y Flora, que no se limitan a la caracterización, sino afectan también a algunas réplicas y situaciones. También encontramos semejanzas entre el súbito cambio de actitud de Melibea y el de Aminta, que el autor pone en relación con un proceso similar al de la philocaptio de la Tragicomedia pero que, sobre todo, tiene que ver con que Aminta ya está enamorada desde antes. De hecho, llega a defender que el proceso de enamoramiento de una y otra protagonista sucede de forma paralela. También señala algunas diferencias importantes: en general, el entremés es más decoroso a la hora de describir los encuentros de los amantes, aunque mantengan varios puntos de contacto con los de Celestina, y rezuma espíritu tridentino al hacer del matrimonio el señuelo con el que se quiere llevar a Aminta a entregarse a Jacinto. Del mismo modo, el desenlace no es trágico, sino relativamente feliz, en cuanto que la burlada ve a sus enemigos castigados, pero precisamente estos castigos son paralelos a las muertes de criados y alcahueta en Celestina. Así pues, aunque sin duda Zayas sigue las convenciones del género en el que escribe, su obra tiene algo apicarado y celestinesco que la autora usa para introducir escenas ligeramente transgresoras y críticas, pero, sobre todo, escenas humorísticas. Más allá de esto falta por completo el espíritu que anima la Tragicomedia. 
2863. GUERRY, François-Xavier, "Ella era el mercader y la mercaduría, ella era la tienda y la tendera": Le vocabulaire érotique marchand dans le cycle célestinesque», Crisol 19 (2021), s.p. [en línea, <https://crisol. parisnanterre.fr/index.php/crisol/article/view/350>, fecha de consulta: 06 de diciembre de 2021].

Análisis del léxico erótico del ciclo celestinesco relacionado con lo mercantil y de lo apropiado que resulta para unas obras en las que el mundo de la prostitución es uno de sus elementos constitutivos y los personajes están involucrados en todo tipo de operaciones comerciales (venta al detalle, intermediación, etc.) e, incluso, en el caso de las clases adineradas, deben su prosperidad a sus negocios. Resulta de especial interés la descripción exhaustiva de las actividades comerciales de los personajes y su contextualización, ya que el ciclo celestinesco no hace un uso meramente convencional de estas metáforas eróticas, sino que estas contribuyen a la caracterización del mundo celestinesco como una sociedad impregnada de lo que podría llamarse una mentalidad mercantilista burguesa.

2864. GUERRY, François-Xavier, "Parece que tienes más confianza en la cerradura de Philomena que en la ganzúa de la vieja Claudina": la porte et ses implications métaphoriques dans le cycle célestinesque (1499-1570)», eSpania 39 (2021), s. p. <https://doi.org/10.4000/e-spania.40524>.

Demuestra la recurrencia de la puerta en el ciclo celestinesco tanto como separación de espacios exteriores e interiores, públicos y privados, y elemento para la situación escénica y marcador de desplazamiento, como como metáfora erótica con larga tradición. Identifica pasajes en los que la metáfora erótica no es evidente, pero de los que podrían extraerse connotaciones sexuales igualmente, que son las más interesantes del trabajo, aunque convincentes en distintos grados

2865. HUERTAS MORALES, Antonio, «Fernando de Rojas y La Celestina a través de la novela histórica: autoría y ascendencia judía», Celestinesca 44 (2020): 145-162. <https://doi.org/10.7203/Celestinesca.44.19431>.

Análisis de las novelas históricas posteriores a 1990 en las que Fernando de Rojas es personaje: Melibea no quiere ser mujer (1991), El manuscrito de piedra (2008) y La judía más hermosa (2005). Se busca identificar la información sobre Celestina y su supuesto autor que se transmite a estas obras contemporáneas, así como qué posiciones toman en aquellas cuestiones críticas que llegan a tocar. En lo relativo al autor, parece haber una especie de consenso sobre la existencia de los «papeles del antiguo autor» y la persecución de la Inquisición. En cuanto a su obra, reaparece el tema de la magia y el del amor hiperbólico, a veces con préstamos textuales, y no son pocos los guiños a sus fuentes más directas o técnicas retóricas más reconocibles. 
2866. KEHREN, Timo, "Calistos Träume: Eros und Thanatos in der Celestina», en Traumwissen und Traumpoetik von Dante bis Descartes, ed. Dietrich Scholler y Jing Xuan. Göttingen: Vandenhoeck \& Ruprecht, 2020, 179-193. <https://doi.org/10.14220/9783737012331.179>.

El artículo continúa las reflexiones iniciadas por Miguel Garci-Gómez y Ricardo Castells. El autor defiende la tesis de que el sueño de Calisto al principio del drama no sólo determina, sino que también anticipa simbólicamente la acción. Para entender el sueño de esta manera, el lector tiene que decodificarlo. Así, la huerta remite al sexo de Melibea, y el halcón al de Calisto. El hecho de que el halcón se haya escapado indica que Calisto ha perdido el control sobre su pulsión. El gerifalte que cae al despertarse Calisto parece estar relacionado con el halcón del sueño. Al mismo tiempo, esta caída anuncia la caída mortal de Calisto al final del drama. El deseo de Calisto se cumple gracias a la intervención de la Celestina. En su conjuro al diablo, la alcahueta vuelve explícita la relación entre sueño, deseo y muerte. Cuando Calisto cae del muro de la huerta de Melibea, se despierta del sueño de la vida, metáfora que ya se encuentra en fuentes clásicas y cristianas [resumen del autor].

2867. LIZABE, Gladys, "'Vendrá el día que en el espejo no te reconozcas": infancia y adolescencia en La Celestina (LC, 1499)", Revista Melibea 13.2 (2019), 71-94 [en línea, <https://bdigital.uncu.edu.ar/15675>, fecha de consulta: 06 de diciembre de 2021].

Recopila las ocasiones en las que los personajes de Celestina hacen referencia a su infancia y adolescencia, mucho más frecuentes para las clases populares que para las clases nobles, con la intención de hacer un retrato de lo que estas etapas de la vida representaban y cómo se entendían en la Castilla de finales del siglo xv. La infancia y la adolescencia están marcadas por las estructuras y las jerarquías familiares, los lazos de sangre o de crianza, la violencia física a manos de los tutores o de otros niños y jóvenes y, en el caso de las clases populares, la precariedad y el pragmatismo. Para las clases acomodadas y las familias que buscaban un futuro para sus hijos en la curia, habría que sumar a todo esto, además, la educación. Pero lo importante no es tanto lo que Celestina nos dice sobre las condiciones de la infancia y la adolescencia como que estas fases se consideran definitorias de los personajes.

2868. LLAMAS MARTÍNEZ, Jacobo, "La Celestina como modelo de Rafael Chirbes en Crematorio", Celestinesca 44 (2020): 163-190. <https:// doi.org/10.7203/Celestinesca.44.19432>.

Estudio comparativo entre Celestina y Crematorio de Rafael Chirbes (2007). Comienza con una exposición de la particular relación del escritor con la obra castellana a través de sus anotaciones a ejemplares 
de Celestina, sus diarios y sus juicios críticos sobre el texto, que nos dejan ver qué aspectos le interesan más, en qué debates críticos toma partido y por qué bando, y cómo interpreta la obra. Sigue con la identificación de potenciales influencias de Celestina sobre la producción novelística de Chirbes, especialmente en Crematorio, tanto si han sido abiertamente reconocidas por el autor como si no, ya sea a nivel de técnica, lenguaje, argumento o de caracterización de los escenarios y los personajes. Por último, se concluye que la lectura de Celestina deja una huella muy marcada en la obra de Chirbes, pero sobre todo en Crematorio, donde se pueden percibir todos y cada uno de sus juicios críticos sobre el texto atribuido a Rojas.

2869. LOBERA SERRANO, Francisco, "El stemma de La Celestina: método, lógica y dudas», en Avatares y perspectivas del medievalismo ibérico, coord. Isabella Tomassetti. San Millán de la Cogolla: Cilengua, 2019, 1697-1716.

Revisión de las limitaciones y la problemática del método estemático aplicado a Celestina, con ejemplos de las dificultades que genera, que sirve también de repaso de la metodología y los principios de construcción y aplicación de un stemma. El autor defiende que la lógica - y un dominio de las circunstancias de composición, difusión y recepción del texto- preside cada decisión del editor. Finaliza con una propuesta de stemma para cinco testimonios (Cue61, Vall61, Alc63, Med63 y Bar66), cuya fijación usa en el artículo para ejemplificar todo lo anterior.

2870. LÓPEZ GONZÁLEZ, Luis F., «The Melancholic Complexion of Melibea», The Modern Language Review 116.2 (2021): 295-315. <https:// doi.org/10.5699/modelangrevi.116.2.0295>.

Analiza el personaje de Melibea desde el punto de vista médico, atribuyéndole una complexión melancólica que le hace especialmente susceptible a sufrir amor hereos. Al contrario que la crítica anterior, el autor afirma que la condición melancólica de Melibea es anterior a su enamoramiento y se manifiesta constantemente en el texto, empeorando a medida que este avanza hasta conducirla al suicidio. Para demostrarlo, se estudian aquellos síntomas melancólicos que no tienen que ver directamente con el amor, sino con la naturaleza, las circunstancias y los hábitos de Melibea.

2871. MATOS, Kevin, «El proceso de amores de Calisto y Melibea frente a la tradición", Celestinesca 44 (2020): 191-250. <https://doi. org/10.7203/Celestinesca.44.19433>.

Examen exhaustivo de la relación entre Calisto y Melibea y de las convenciones literarias con las que conversa, sea para respetarlas o para transgredirlas. Su comportamiento pondría de manifiesto la con- 
tradicción entre lo protocolario del cortejo amoroso y la naturaleza espontánea y fisiológica - $;$ animal? - de su deseo, que en el caso de Melibea contraviene además las convenciones impuestas a su género. Muy útil para ubicarse tanto bibliográfica como contextualmente en el tema del amor en Celestina gracias a su amplitud y manejo de las fuentes primarias y secundarias.

2872. MATOS, Kevin, «A vueltas con el amor y el gozo en la Tragicomedia de Calisto y Melibea». Nueva Revista de Filología Hispánica 69.2 (2021): 797-822. <https://doi.org/10.24201/nrfh.v69i2.3756>.

Defensa de una lectura hedonista de Celestina apoyada en argumentos de la filosofía naturalista universitaria. El autor alude al carácter convencional, literario y paródico y/o humorístico de los textos contemporáneos en los que apoya su argumentación (el Tratado de cómo al hombre es necesario amar y, sobre todo, el Breviloquio de amor e amicicia, pero también alude a géneros cortesanos) y concluye que, si en estos todo está supeditado al amor y el amor es inevitable, Celestina puede ser leída como un canto a esa inevitabilidad. Esto permitiría alinearla con los tratados naturalistas y restar importancia al didactismo.

2873. MIAJA DE LA PEÑA, María Teresa, "Memoria y olvido en La Celestina», en Avatares y perspectivas del medievalismo ibérico, coord. Isabella Tomassetti. San Millán de la Cogolla: Cilengua, 2019, 1425-1436.

Ampliación de los estudios sobre los papeles de la memoria y el olvido en Celestina. Por un lado, la evocación y la omisión selectivas, tanto de un pasado real como de uno imaginado, son herramientas fundamentales del oficio de la alcahueta. Por otro, lo que los personajes recuerdan (o creen recordar) u olvidan (o ignoran o escogen ignorar), sobre Celestina o sobre otras cosas, resulta fundamental para sus decisiones. Se concluye que el olvido resulta más determinante que el recuerdo a la hora de que los personajes tomen las decisiones que los llevarán a su trágico fin.

2874. MORENO LAGO, Eva, "La Celestina a escena: reflexiones en torno a la adaptación teatral de Alfonso Zurro", Anagnórisis 22 (2020): 407-422 [en línea, <http://anagnorisis.es/pdfs/n22/MorenoLago_num22(407422).pdf>, fecha de consulta: 06 de diciembre de 2021].

Análisis detallado de la adaptación teatral de Alfonso Zurro y para la Compañía de Teatro Clásico de Sevilla (2008). Además de a las dificultades propias de adaptar Celestina (longitud, división bastante aleatoria en autos, toma de postura interpretativa, lenguaje alejado del público, etc.), Zurro se enfrenta al problema añadido de disponer de un tiempo y número de actores muy limitados, a todos los cuales se enfrenta con diferentes estrategias, que son las que se comentan en el 
artículo. Logra cierto equilibrio entre la fidelidad al texto y la innovación dramática, pero no tanto como otras obras de la Compañía.

2875. NAVARRO DURÁN, Rosa, «Siguiendo el guion, pero guardando el decoro: cuchilladas y libreas en la Tercera Celestina», Celestinesca 44 (2020): 405-430. <https://doi.org/10.7203/Celestinesca.44.19442>.

Gaspar Gómez continúa la Segunda comedia de Celestina de Feliciano de Silva de tal manera que se restaure el orden social que su antecesora había trastocado al no castigar a Celestina por sus acciones y permitir que la pareja protagonista se casara en secreto. Por la mayor parte, el artículo es un estudio comparativo de ambas obras en el que se destaca sobre todo el ennoblecimiento de los personajes (especialmente, los amantes, pero también Celestina, ascendida de alcahueta a casamentera) y del desenlace (matrimonio religioso y muerte-castigo de Celestina por accidente), y el arrufianamiento de los personajes bajos, cuya condición marginal quiere destacar el autor no permitiendo que se mezclen con los personajes nobles y dando mucha más importancia al decoro en la caracterización de los personajes. Todo esto contribuye a que la obra resulte mucho más decente.

2876. PAOLINI, Devid, "Algunas nuevas sobre Alphonso Hordognez", Celestinesca 44 (2020), pp. 251-264. <https://doi.org/10.7203/Celestinesca.44.19434>.

Complementa el artículo de Gesiot (2019) sobre las deudas de la dedicatoria de la traducción italiana de Celestina para con el Decamerón y Tirant lo Blanch, poniendo de relieve las deudas para con los paratextos de la propia traducción. El autor usa estas influencias para reforzar la potencial relación de Alphonso Hordognez con Urbino y la posibilidad de que fuera originario del levante peninsular, así como para sugerir que Hordognez tal vez pudiera haberse planteado traducir Tirant lo Blanch al italiano.

2877. RAMÍREZ, Álvaro y Costanza GISLON DOPFEL, «The Intellectual Procuress: Celestina's Legacy and the Rhetoric of Seduction", Avisos de Viena 2 (2021), $81-89$ [en línea, <https://journals.univie.ac.at/index.php/ adv/article/view/6188>, fecha de consulta: 11 de diciembre de 2021]

Tras analizar el tema del burdel y de la proxeneta en la pintura holandesa del siglo XVII, con particular interés en algunos cuadros de Jan Vermeer, el artículo muestra cómo la obra maestra española es el punto de partida de una nueva visión del arte y la literatura: el personaje de la alcahueta y su oratoria serían el medio que permitirían al autor volverse consciente de su capacidad de controlar a los demás a través del deseo. La segunda parte del trabajo se ocupa brevemente de la influencia de $L C$ en los diálogos de Aretino, en la Raffaella de Alessandro Piccolomini y en el Specchio d'amore de Bartolomeo Gottifredi. 
2878. RODILLA LEÓN, María José, "Las cortesanas romanas, clientas del afeite lozanesco, y otras alcahuetas de los siglos áureos», en Dueñas, cortesanas y alcahuetas: "Libro de buen amor", "La Celestina" y "La Lozana andaluza». Alcalá la Real: Ayuntamiento de Alcalá la Real, 2017, 335342 [en línea, <https://cvc.cervantes.es/literatura/arcipreste_hita/05/ rodilla.htm>, fecha de consulta: 23 de octubre de 2020].

Trata, en particular, de las artes de la cosmética, llamando en causa a diferentes alcahuetas y obras desde la antigüedad romana hasta finales del siglo XVII.

2879. ROMERO, Loreto, «Rapture and horror: Reading Celestina in sixteenthcentury Spain", en The Routledge Hispanic Studies Companion to Medieval Iberia: Unity in Diversity, ed. E. Michael Gerli y Ryan D. Giles. LondonNew York: Routledge - Taylor \& Francis Group, 2021, 491-507.

Acercamiento a Celestina desde la interpretación de Julia Kristeva de lo abyecto como aquello que a la vez atrae y repele. Se destaca cómo el texto es fuente de distintos placeres (textuales, morbosos, sensuales, etc.) sin dejar de tener sus momentos horrorosos (muertes cruentas supuestamente ejemplarizantes). Esta interpretación se extiende a cómo los propios personajes, igual que los lectores, también se recrean en lo abyecto, representado sobre todo por la alternancia entre gozo y muerte. Se usa esta particularidad para defender que la intención didáctica del texto no es lo único que motiva la presencia de lo abyecto, que busca también el disfrute del lector, así como para explicar la prevención moral contra la lectura de Celestina y su difusión masiva gracias a la imprenta. Para terminar, se defiende que los continuadores e imitadores también se recrearon en este aspecto de lo abyecto, cada uno desde sus propia perspectiva ético-moral.

2880. ROUHI, Leyla. "Literary Shifts On La Celestina and English Translations». Estudios del Observatorio, 2021, 1-25 <http://dx.doi. org/10.15427/OR067-01/2021EN>; [también en traducción española: $<$ http://dx.doi.org/10.15427/OR067-01/2021SP>].

Comentario de las introducciones de algunas traducciones contemporáneas de Celestina al inglés, con especial énfasis en las orientadas a un público americano. El objetivo es identificar los aspectos que se destacan en cada una de ellas y cómo el trasfondo cultural de los lectores objetivo influye en qué se resalta en cada introducción para llamar su atención, pero también la lectura que el propio traductor hace del texto, las posturas que adopta en los grandes debates de la crítica celestinesca y sus propias convicciones éticas y/o morales. Todo esto contribuye a hacer accesible el texto a un público angloparlante. 
2881. RÜDINGER Castro, Paula, «La Celestina de Fernando de Rojas: aspectos de la vida y obra del autor: conclusiones transgresoras», liLETRAd 5 (2019): 235-238.

Comentario bastante genérico, y a veces cuestionable, sobre algunos aspectos relacionados con el autor y la obra.

2882. SAGUAR GARCÍA, Amaranta, "Hacia un censo completo unificado de los ejemplares conservados de Celestina (I): ejemplares de ediciones en castellano localizables en línea», Celestinesca 44 (2020): 265 318. <https://doi.org/10.7203/Celestinesca.44.19435>.

Censo que reúne un total de 476 ejemplares de ediciones de Celestina en castellano localizables en los catálogos electrónicos de las colecciones correspondientes (con algunas informaciones adicionales sobre ejemplares perdidos o no localizados y potenciales ediciones desconocidas) a fecha de 1 de noviembre de 2020. Para cada ejemplar se consigna la ciudad, la biblioteca, la signatura (enlazada o no al catálogo correspondiente) e información sobre el estado del mismo. Igualmente, se recogen los enlaces a los facsímiles digitales de algunos de ellos.

2883. SAGUAR GARCÍA, Amaranta, y Devid PAOLINI, "Celestina: Documento bibliográfico (suplemento número 42)», Celestinesca 44 (2020): 361-384. <https://doi.org/10.7203/Celestinesca.44.19439>.

Último suplemento bibliográfico que desde 1985 ya cuenta con 2834 entradas.

2884. SALVADOR MIGUEL, Nicasio, "La Celestina", en Historia del teatro español. I. De la Edad Media a los Siglos de Oro, ed. Abraham Madroñal y Héctor Urzáiz. Madrid: Gredos, 2003, 137-167.

Un detenido estudio de los temas principales que conciernen a $L C$ ("La trama», "El estudio de la obra», "El texto», "La redacción de la obra. El paso de Comedia a Tragicomedia», "La fama de Rojas como autor», "El Auto de Traso», "Fernando de Rojas, autor de La Celestina», «El género», «Fuentes», «La ambientación, la lengua y los personajes» $\mathrm{y}$ "La intencionalidad»).

2885. SÁNCHEZ PÉREZ, Claudia Isabel, «La inteligencia emocional de la Trotaconventos. Buhoneras, alcahuetas y sanadoras en la Baja Edad Media», en Dueñas, cortesanas y alcahuetas: "Libro de buen amor»" "La Celestina" y "La lozana andaluza». Alcalá la Real: Ayuntamiento de Alcalá la Real, 2017, 373-382 [en línea, <https://cvc.cervantes.es/literatura/arcipreste_ hita/05/s_perez.htm>, fecha de consulta: 23 de octubre de 2020].

El trabajo analiza históricamente el papel de la mujer en la Edad Media con especial atención a la figura de la alcahueta tomando las riendas de la Trotaconventos del Libro de buen amor. 
2886. SCARBOROUGH, Connie L, «Melibea Lies», Celestinesca 44 (2020): 319-346. <https://doi.org/10.7203/Celestinesca.44.19436>.

Retrato de Melibea como mentirosa. Desgrana las diferentes situaciones en las que Melibea miente, a sí misma o a los demás. Estas mentiras contribuyen a su trágico final, ya que este constante mentir influye sobre su capacidad de valorar las consecuencias de sus actos y, por lo tanto, sobre las decisiones que tanto ella como los personajes que la rodean toman a lo largo de la obra, que son las que precisamente acabarán provocando su suicidio al final.

2887. SHAFIK, Ahmed, «Umm Rašĩd la casamentera y alcahueta: paralelismos y diferencias con Celestina». Al-Andalus Magreb 27 (2020), ensayo núm. 105, 1-16. <https://doi.org/10.25267/AAM.2020.v27.05>.

Estudio comparativo que ubica a Celestina en la tradición de las medianeras orientales mediante su comparación con Umm Rašīd, protagonista de Țayf al-Jayāl de Ibn Dāniyāl (ca. 1300), una pieza de teatro de sombras con la que la Tragicomedia tiene algunos puntos en común. Solventa algunas carencias del artículo de Víctor de la Lama (1996) y hace una comparación detenida de los dos personajes que pone de manifiesto que, además de muchas similitudes, tienen también algunas diferencias que probablemente tengan que ver con los distintos contextos a los que se destinan: un público letrado en el caso de Celestina y un público más popular en el caso de Tayf al-Jayāl.

2888. SOLER BISTUÉ, Maximiliano, "A mí me sé conocer": autoconocimiento, deseo, subjetividad femenina en la Tragicomedia de Calisto y Melibea", eHumanista 43 (2019): 365-375 [en línea, <https://www.ehumanista.ucsb.edu/sites/default/files/sitefiles/ehumanista/volume43/ ehum43.soler.pdf $>$, fecha de consulta: 06 de diciembre de 2021]

Lectura de género de Celestina centrada en la autopercepción de los personajes femeninos de Areúsa y Melibea. Según el autor, a pesar de las evidentes diferencias de estatus social de las dos mujeres, ambas coinciden en su conciencia explícita de su individualidad y en proferir sendos discursos de autoafirmación en diferentes momentos de la obra, discursos que, además, exponen a las claras su propia pulsión sexual. Tras comentar estas intervenciones y lo que nos revelan sobre los personajes, concluye que su autorrealización es una exposición de los peligros y de las contradicciones que este autoconocimiento lleva asociado dentro de una sociedad patriarcal que no deja de ver a las mujeres como mercancías.

2889. TAYLOR, Barry, "Kaspar von Barth, Latin Translator of $\mathrm{La} \mathrm{Ce-}$ lestina (1624), and Concepts of Canonicity in the Seventeenth Century", eHumanista 48 (2021): 231-240 [en línea, <https://www.ehu- 
manista.ucsb.edu/sites/default/files/sitefiles/ehumanista/volume48/ ehum48.f.taylor_0.pdf $>$, fecha de consulta: 06 de diciembre de 2021]

Una breve presentación de la traducción de Celestina al neolatín de Kaspar von Barth y de su importancia a la hora de canonizar la obra, y un repaso rapidísimo de su vida, su obra y su perfil intelectual, sirven al autor para introducir el tema de la influencia de las traducciones neolatinas de obras en castellano de Barth sobre la propia producción de Robert Burton, así como los paralelismos vitales e intelectuales entre ambos.

2890. TAYLOR, Ordner W. III, «Intemperance and the Path of Villainy in La Celestina», The Lincoln Humanities Journal 78 (2019): 174-184 [en línea, <https://www.lincoln.edu/sites/default/files/pdf/cahss/Lincoln-Humanities-Journal-Vol-7-2019.pdf $>$, fecha de consulta: 06 de diciembre de 2021].

Comentario desde el punto de vista de la falta de templanza de los personajes y sus consecuencias morales. Elabora ideas anteriores sobre el simbolismo del halcón de Calisto y sobre la relación de causalidad acción-castigo, para acabar defendiendo la finalidad didácticomoral de Celestina. No aporta nada nuevo, pero sí extiende de una manera bastante inteligente algunas ideas preexistentes a pasajes en los que no se habían aplicado.

2891. TORRES MARTÍNEZ, José Carlos de, «La pura comicidad en una continuación celestinesca: La Lena o El celoso de Diego Alfonso Velázquez de Velasco (Milán 1602)», en Dueñas, cortesanas y alcahuetas: "Libro de buen amor", "La Celestina" y "La lozana andaluza». Alcalá la Real: Ayuntamiento de Alcalá la Real, 2017, 423-432 [en línea, <https://cvc. cervantes.es/literatura/arcipreste_hita/05/torresmartinez.htm>, fecha de consulta: 14 de septiembre de 2019].

Análisis de la influencia celestinesca en una obra de principios del siglo XVI: La Lena (titulada también El celoso) de Diego Alfonso Velázquez de Velasco.

2892. XIAO, Yang, "Del deseo sexual y de la enfermedad de amor entre Calisto y Zhang Junrui», En Textos e imágenes de China, ed. Blanca Puchol Vázquez, Madrid, SELGYC, 2020, 60-81 [en línea, <https:// www.selgyc.com/mat/2letraschinas/selgyc_letraschinas_05xiao. pdf $>$, fecha de consulta: 06 de diciembre de 2021].

Trabajo que continúa los estudios comparativos del autor sobre Celestina e Historia del ala oeste, en este caso desde el punto de vista fisiológico del amor y el deseo sexual. Establece un paralelismo entre los personajes de Calisto y Zhang Junrui y demuestra mediante citas tex- 
tuales - y, en el caso de Celestina, referencias a la crítica preexistente sobre el tema- la naturaleza sexual del amor de ambos personajes. También describe los comportamientos de los personajes que pueden relacionarse con el concepto de "enfermedad de amor» en cada uno de los contextos culturales correspondientes. Sin embargo, esto se hace sin establecer una verdadera comparación, en espera de que el lector vea por sí mismo los paralelismos. Al final, el autor hace una recapitulación de las similitudes y las diferencias, pero se queda en eso, sin que haya un verdadero análisis comparativo. 